The original of the above holograph letter, with envelope addressed by Mr. Darwin and duly postmarked, along with the proof sheet of the first copperplate form to receive finger-prints, made for me in Japan, is now in the Library of the Royal Faculty of Physician and Surgeons, Glasgow. On October 28th, in Nature, appeared a contribution by me, "On the Skin-furrows of the Hand," which was printed in the Index Medicus of the United States as the first recorded contribution on that subject. At the International Medical Congress, about ten montbs afterward, Dr. Billings, then editor of the Index, said, in a speech: "Just as each individual is in some respects peculiar and unique, so that even the minute ridges and furrows at the end of his forefingers differ from those of all other forefingers, and ar sufficient to identify," and so on. (Report in The Times, August 5th, 1881.) My proposal was certainly the first public suggestion to establish a scientific method of identification on the basis of finger-prints. Sir William Herschel wrote soon afterward to Nature, admitting my priority of publication, but stating that he had used a method of finger-prints in India before this. There is no dispute between Sir William Herschel and myself, as each had reached his own conclusions quite indeNature (October, 1894) and in Gegenbauer's Jahrbuch for 1905, in which the date of my first contribution is considered the starting-point of recent study of the subject. In 1881, Monsieur Bertillon, of Paris, brought out his delicate anthropometric system, to which the independent finger-print method from England was superadded. The finger-print method alone was used in a United States expedition in 1882, and it was tried in San Francisco, as afterward in South Africa, to identify the fluctuating population of Chinamen. In the year after my final return to England greatly renewed interest was aroused in the subject. Herbert Spencer tried to explain the origin of the ridges in an article in The Nineteenth Century, May, 1886. Sir Francis Galton, to whom Charles Darwin wrote to me in 1880 that he whom Charles Darwin wrote to me in 1880 that he
would refer the matter, began the study, as he states on page 2. of "Finger Prints," in 1888. In that same year, Inspector Tunbridge from Scotland Yard was fficially appointed to investigate my proposals. No report has ever been made public, but Mr. Tunbridge old me that he feared the method was too fine to work, and said that nothing could be done, at least without fresh legislation. Some years afterward he was appointed to New Zealand, where he was the means of inducing the prison authorities and police to apply the method, which has been now in successful operation all over Australasia for some years; so Mr. Tunbridge wrote to me in 1907.

In 1894, a committee appointed by Mr. Asquith met and finally, after some rambling conclusions, adopted Bertillonage with finger-prints as some help, the former being used as the basis of classification. The proposal was absurd, and it was soon found, as might have been foreseen, that finger-print patterns yield a far firmer and more searching basis of classification in themselves than the other method, and need no auxiliary crutches.

In 1897, the two associated methods began to be applied in British India; while in civil cases there, as in attestations, pension claims, and so on, the fingerprint method was used by itself.

In 1901, the ten-finger method in serial order, exactly as originally advocated by me in 1880, was finally adopted in England, after other trials, and has met with an immediate and triumphant success in giving rapid and easy identifications of recidivists or old professional criminals, often living under aliases. Monsieur Bertillon, who at first did not use finger-prints at all, wrote to me officially that since 1894 the two methods had bee jointly used in Paris, and that greater security was now felt in identifying. In 1902, finger-prints took th place of bodily measurements in Austria-Hungary, bein easier of application, and less likely to give varying results. Two years afterward Spain followed suit. The method had been worked before that period in Buenos Aires with success. A private service for identification by the finger-print method was, I believe, instituted in Belgium by Dr. de Laveleye, but I have heard no report of results.

It is a curious fact, but true beyond question, that the effectiveness of the method has proved to be the chief obstacle to its more extensive application. In short, it miraculous effect in tearing the mask from old criminal who try to veil their identity by an alias, has created horror of it among the class from which many recruit used to be drawn for army and navy.

In conclusion, I should like to point out that ther are five distinct ways in which Dactylography, as the scientific study of finger furrows is called, may be erviceable:

(1) In relation to the problem of human lineage. Much tentative work has been now done in this field by many workers, and a scientific pathway begins to open p before us.

(2) In elucidating the relations of front and hind limbs; Prof. Bowditch, of Harvard, wrote to $\mathrm{m}$ that he had early begun an inquiry into this subject. It promises to yield results of interest, but more workers are required.

(3) In identifying for life insurance, pensions, passports, affidavits, cheques, signing deeds, and so on. Again, in identifying the dead by former records, after battle, flood, fire or earthquake

(4) In identifying old convicted criminals who have assumed other names.

(5) In testing evidence of bodily presence at a scene of crime by bloody finger-marks, sweaty or greasy smear on glass windows, wine glasses, lamps, or cash boxes paraffin and 0 on. Faint impresses oan be revived invisible means; impri means; imprints in relievo may be photographed and made clearly intelligible
smudge from a finger.)

The last, and I think by far the least, of these once potential, now actual, utilities has taken the deepest hold of the popular imagination, and has seemed, to me at least, to threaten some danger to the innocent by its of ten ignorant and unscientific application. The method is not "mathematical," as certain officials are never is not "mathematical," as certain officials are never use of their own eyesight and mother wit by the plain men in the jury box. It is essentially English, and every accused person in the dock is as able as a judge, or counsel, or official witness, to test its validity.

\title{
The Genesis of the Rare Earths
}

\section{Their Relation to the Earth's Past History}

\section{By Dr. R. Böhm}

In spite of the large monazite sand deposits in Brazil, the total quantity of all the rare earths probably does not exceed all told 1/1,000,000 per cent of the entire crust of the earth. When the latter was still in a heated state, composed of a mixture of all the elements, the atoms probably united to form the principal components of the earth's crust. In that condition the rocks formed gradually and slowly, taking their origin from those materials which were most widely and largely scattered throughout the mass, and in this way the granites, quartzes, the gneisses, the feldspars and the micas came into existence. These feldspars and the micas came into existence. Thes into each other and were raised high up into mountain ranges of gneiss, granite and other primary rocks. The other component parts of the magma of the earth could not keep pace with the growth of the more common and larger kinds of rocks. They had to search too long for their chemical affinities. Auer von Welsbach in his experiments with the salts of thorium, was able to prove an enrichment or concentration of the traces of cerium, which had been present in the thorium in the mother lye, and thus the less or least largely represented ingredients of the fluid magma, which here represented the mother lye of the crystalline formation, were concentrated. Then began a process of selective crystallization, during which the rarer ores and minerals, for whose recovery we are now digging and searching through the primitive rocks, were formed. Thus the shining particles of gold passed into quartz, and the modest little dark crystals of monazites, thorites, gadolinites, euxenites, and other derivatives of the rare earths were saturating the granite. However small their dissemination in the magma may have been, in the end like aggregated with like, and the rare earths were safely imprisoned in the grasp of the powerful giant granite. But at this time another younger and still more powerful, giant appeared upon the scene and began to fight an obstinate war with granite, which lasted millions of years. This young giant was the water. Without rest or interruption, swift and mobile, yet fighting with untiring perseverance, he renewed his attacks on the old granite again and again, and though his advances were but slow, he always remained victorious, and every year his armies, the rivers and rivulets, carried all the loose material which the gran.

* Abridge from the Zeitschrift fur anegwande Chemie. ite held imprisoned, down into the valleys. Among those that were freed by the water were also the minerals of the rare earths, and every once in a while some of them would bid farewell to their old prison and migrate in company with the quartzes and feldpars, whose numbers were so great that the stranger quite disappeared among tnem. But when we bea in mind the long ages during which these forces have been working, it becomes plain that gradually quant ties of rare earths, which for us seem immense, must have been washed into the sedimentary rocks. But though large in themselves, these quantities, compared with the thousands of millions of tons of solid matter which finely ground covered the crust of the earth, seem very small. The rare earths were in fact a firely disseminated as before, and any possibility of finding them and proving their occurrence seemed to be out of question.

And yet it was possible to find again what seemed to be lost forever. The organic power of nature found it possible to enrich the infinitely small traces of rare earths in the surface soil, so that it has been found within our means to prove their occurrence. Just as sea weed attracts and accumulates the infinitesimal particles of iodine in the sea water, so the plants' hunger for mineral substances has concentrated the salts of the rare earths and absorbed them as parts of the organic structure of the plants, using the decomposing faculty of the roots as an agent. Cossa, the Italian physiologist, has been able to prove that the rare earths, especially the cerite earths, are presnt in very small quantities in the ashes of plants and bones. This is the end of nature's organic reduction process and in this way the very rare mineral cerite, thorite, and monazite have been found in the sand strata of very great thickness in Brazil, Ans tralia, North America, and the Ural Mountains, where nature has eliminated and deposited the heavy monaite sands from the corrosion and decomposition prodicts of the rocks. The monazite sand is also associated with gold, an occurrence which finds an eas explanation in what has been said above. The gold districts of Carolina contained wash drifts of th mountain rivers, showing a sand which consists mainly of brown or yellowish brown crystals. This socalled monazite sand had already attracted the attention of the miners, at a time when gold washing wa in full swing, by its heavy weight, but it had been thrown aside as worthless until the genius of Auer von Welsbach recognized its real value.

The commercially important monazite sand deposits lie in the alluvial detritus of the rivers and their sub-soils, as well as in the sand deposits along the sea coast. Such deposits could only have been formed in countries which remained immune from the erosive action of prehistoric glaciers. The latter at one time covered a large portion of the earth's surface, especially in the northern hemisphere. In the countries lying outside of the limits of these prehistoric glaciers, the soft surface layer of the decomposed rocks remained in their original position, excepting of course, the changes caused by the action of the running water. These surface layers of detritus (also called saprolith, i. e., rock decomposed but not washed away) often reach a thickness of 50 to 200 feet. Owing to water erosion these saproliths have been further broken up, and were carried down into the river beds and their sub-soils. There the material is subjected to a further natural eliminating and concentrating process, the heavy matter being deposited first. Wherever the saproliths carried monazite, this mineral has, owing to its great specific weight, accumulated together with other minerals such as titanium. oxide, granite, feldspar, and quartzite. The process by which sandbanks are deposited in the sea is similar in nature. Sea waves, when breaking against monazite-bearing, crystalline sands, loosen the latter, and, washing away the less heavy earths and minerals, leave along the coast concentrated deposits of monazite sands, mixed with greater or less quantities of ther minerals.

To-day the designation "rare earths" hardly has the same meaning it had a little while ago, especially, at the time when the incandescent gas light, in whose production some of the rare earths play an important part, was first invented. At present we are acquainted with about one hundred minerals containing rare earths. But, of course, when we compare them in quantity with other kinds of earths, we can still give them the designation "rare earths," even though their quantity and number is considerable.

AT the beginning of 1910 the United States, where there is no State telephone monopoly, had 7,000,000 telephones for a population of $80,000,000$, or 87 telephones for 1,000 Inhabitants. - The Engineer. 